\title{
Notas sobre Campo Adentro, a los 10 años de su inicio
}

Fernando García Dory | artista y agroecólogo, creador de Campo Adentro

URL de la contribución <www.iaph.es/revistaph/index.php/revistaph/article/view/4486>

\section{RESUMEN}

Hablar de un proyecto como Campo Adentro puede ser una vía para examinar posibles estrategias culturales y artísticas en relación a la cuestión rural de hoy.

A partir de ahí podemos ver las condiciones en las que surge un nuevo campo de práctica de arte en el medio rural, sus referentes históricos y objetivos, así como ejemplos concretos de práctica situada.

\section{Palabras clave}

Agroecología | Arte | Campo adentro | Ciudad | Despoblamiento | Espacios rurales | Nueva ruralidad | Territorio | 
Introducción de Fernando García-Dory a Mono/permaculturas: ontologías de la diferencia. Cuadernos de Campo N-1. Servicio de Publicaciones de Campo Adentro, 2013.
Hablar de un proyecto como Campo Adentro puede ser una vía para examinar posibles estrategias culturales y artísticas en relación con la cuestión rural.

Lo rural es algo que sobrepasa las delimitaciones geográficas o demográficas, o económico-territoriales, para ser un ámbito de generación de pensamiento, de elaboración cultural, proyección, existiendo indistintamente en el campo, en la ciudad o en lo rurbano.

En lo rural encontramos una forma de experimentar y confrontar algunos de los cruciales retos contemporáneos a los que nos enfrentamos en nuestro modelo civilizatorio.

Por otro lado, es a partir de estéticas transformadoras que podrían movilizarse visiones, valores y consensos para la construcción de un nuevo paradigma.

En resumen, dicho constructo cultural toma del decrecimiento, comunalismo, teorías del buen vivir y de la transición a un sistema de mayor equilibrio ecológico y territorial, con una participación activa de la ciudadanía y una nueva noción de economía. Se trataría de una fase más allá de la modernidad y del sujeto individual atomizado y racionalizante, parte central de regímenes de estado liberales, sin caer en la supermodernidad, con su fe en la biología sintética, las redes inteligentes, las soluciones TED o el revival de una trasnochada carrera espacial, ni en la tautología nihilista de la posmodernidad. Se trataría de una transmodernidad entendida en el contexto de la filosofía de la libertad de Enrique Dussel, asociada a la búsqueda de la identidad latinoamericana. Se entienden entonces estas teorías transmodernas "como las procedentes del Sur Global, que reclama un lugar propio al margen de la modernidad occidental, incorporando la perspectiva de lo postcolonial subalterno, muy incrustadas las cosmovisiones outsider, ecofeministas, y campesinas e indígenas"1.

Para empezar a acotar lo que entendemos por arte, sus centros -en el sistema del arte contemporáneo- y puntos de fuga de esta modernidad tardía (o irrealizada, si atendemos a Bruno Latour), valga también acercarse a Campo Adentro (traducido como INLAND al inglés). Tiene en sí mismo una naturaleza difícil de captar, siendo multiforme, cambiante, capaz de adoptar numerosas banderas de conveniencia como táctica intencionada para permanecer inaprehensible, difuso y camuflado.

Se define como un proyecto artístico sobre una organización, o una para-institución, que es en parte movimiento social, en parte start-up. Es también un colectivo y una plataforma de colaboración, una red de espacios que albergarían comunidades-de-práctica y una agencia móvil de creación inserta 


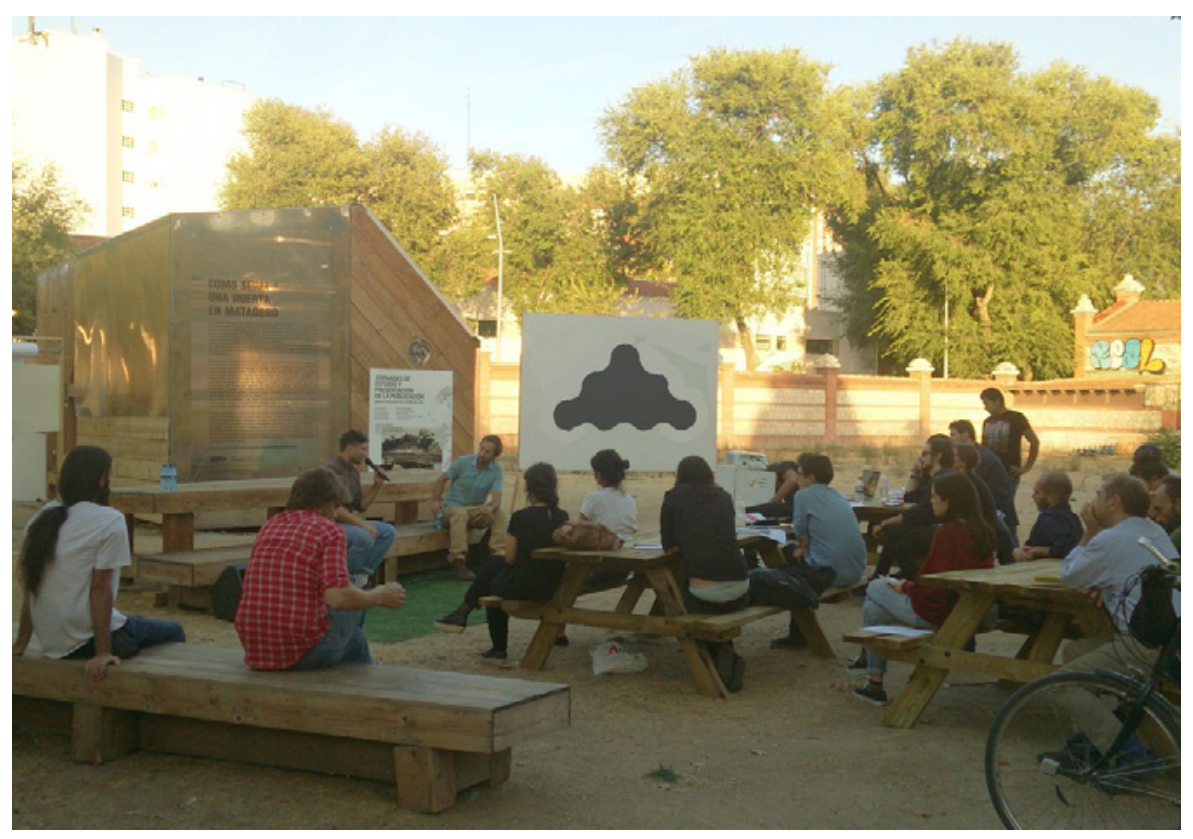

en las dinámicas del campo del arte. Podría ser una representación de un "estado dentro del estado", un sistema autosostenido y replicable inspirado en Hezbollah, un modelo a escala, un gesto simbólico o una escultura social funcional, útil.

Campo Adentro comienza en 2010 teniendo como punto de partida la posible cuestión de ese reencuentro entre arte y producción cultural, por un lado, y campo y producción agraria, por otro, en la contemporaneidad. Surge para mí sobre la brecha entre ambas realidades que pude percibir al crecer entre campo y ciudad, acompañando a pastores y remanentes de la cultura campesina en Picos de Europa y estudiando Bellas Artes en la Universidad de Madrid.

Precisamente por la sinrazón aparente de esa lejanía e incomunicación comencé a implicarme en 1999 en la Plataforma Rural, un movimiento social por un medio rural vivo. Ese mismo año inicio un primer proyecto que experimenta sobre la intersección arte-agroecología y plástica social en el sentido que le da Joseph Beuys. Se trata de una cooperativa de producción-distribución-consumo llamada Bajo el Asfalto está la Huerta. En 2006, tras convocar y celebrar la constitución de una Comisión de Arte y Medio Rural en el seno de la Plataforma Rual, se escribe un manifiesto, que creo aún de gran valor, y se organiza un acto en La Casa Encendida en Madrid, presentando la cuestión.

Podemos destacar dos cosas sobre este inicio: una es que brota de una necesidad en el seno de la lucha en un movimiento social, y otra que surge
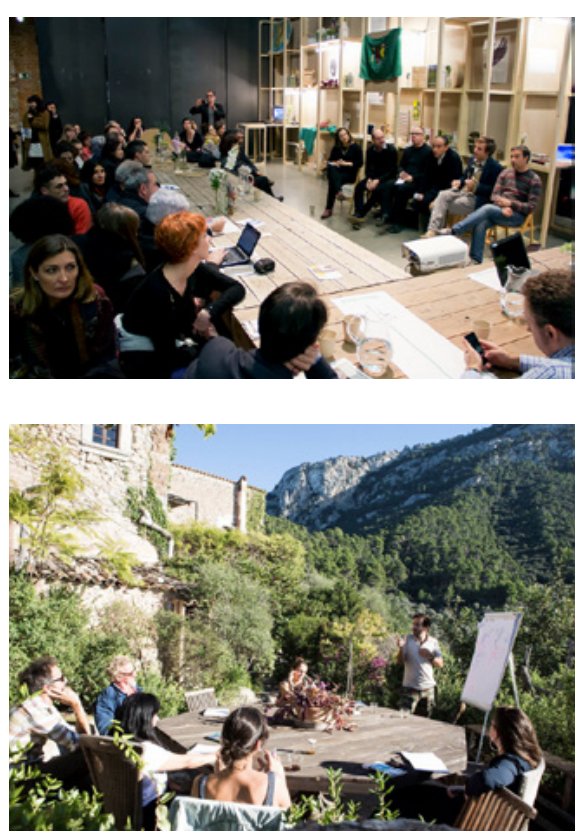

Diferentes encuentros y talleres de Campo Adentro, en Madrid Nuevo Jardin de Dalias, Mallorca y en Matadero Madrid | fotos Campo Adentro 
2

En su definición más oficial, aunque algo críptica, se dice que responde a un manifiesto de tres términos: arte, agricultura-territorio y cambio social ("Acerca de" en http://www. inland.org/es> [Consulta 30/09/2019].

Hasta ese momento en nuestro país principalmente se hablaba de "arte y naturaleza" habiendo espacios de arte en el campo pero que funcionaban al margen de los discursos ruralistas y de la agroecología

3

Surge un entramado académico-técnico independiente como el Consorcio Latinoamericano sobre Agroecología y Desarrollo (CLADES), con Miguel Altieri a la cabeza; y en España, Eduardo Sevilla Guzmán fundó e Instituto de Sociología y Estudios Campesinos (ISEC), muy involucrado con el movimiento de ocupación de latifundios por parte del sindicato de jornaleros de Andalucía (SOC)

4

Partiendo de que parecen haberse alcanzado los límites no solo del crecimiento económico, sino del arte que este sistema exuda en la forma de "arte contemporáneo", en tanto campo autónomo que distinguió Bourdieu, sus dinámicas de producción, circulación y consumo. Se caracteriza también por la recuperación de toda estética disidente y el pensamiento crítico por parte de un establishment que se debe a la lógica del espectáculo, como ya señalo hace medio siglo Guy Debord.

La otra cara por tanto de la misma cuestión sería en qué medida puede el movimiento ruralista y el legado de los saberes campesino-indígenas, y una nueva relación con el territorio que se alimente de nuevas corrientes en el pensamiento crítico como es el post-humanismo, el nuevo materialismo, la ecocrítica y el nuevo ambientalismo , o la teoría post-coIonial, dar base a un proceso de re-generación del sistema arte y de las formas de ser "artista" y producir cultura.

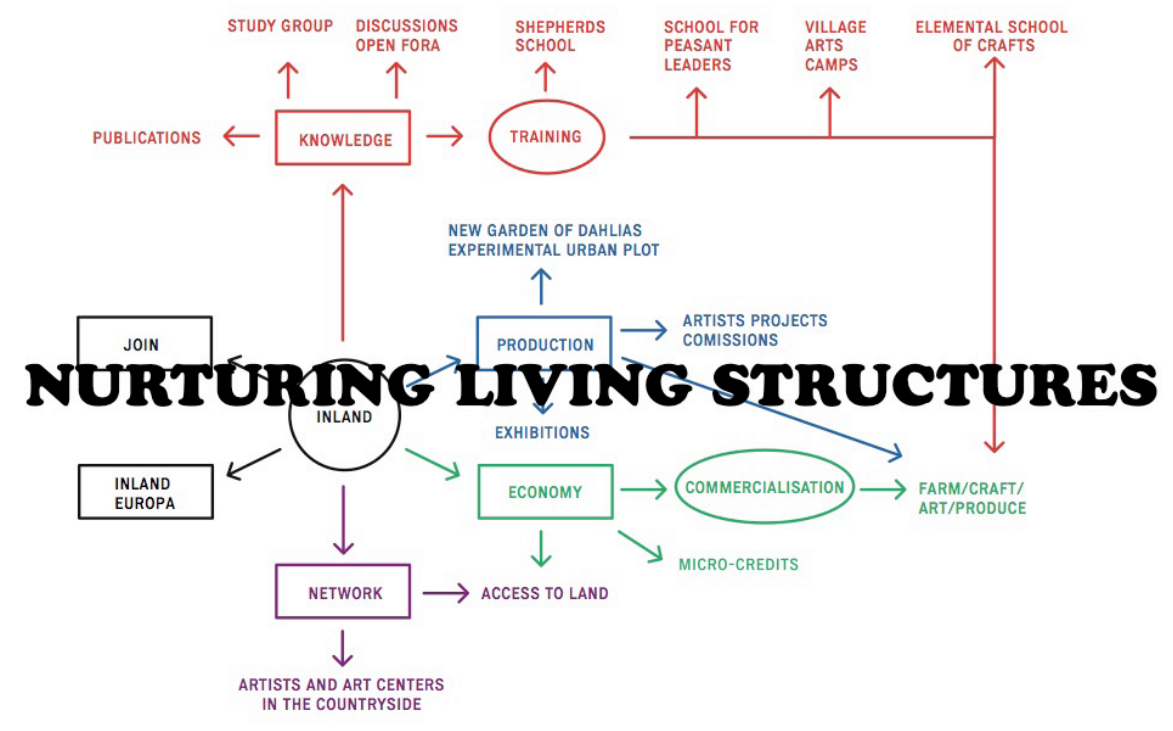

Diagrama de funcionamiento, Fernando García Dory 2013

forjando una forma de entender el binomio arte y medio rural/territorio que se diferencia de lo existente hasta este momento en el panorama español, y que plantea una visión más compleja y elaborada de este campo de práctica, cuya concepción empieza ahora a estar más generalizada².

Sobre lo primero, se trata de un camino paralelo al propio surgimiento de la agroecología, como ciencia de un nuevo paradigma, y que toma forma al fragor de resistencias rurales del movimiento campesino indígena en la década de los 80 , sobre todo en América Latina, sur de Asia e incluso en nuestro país ${ }^{3}$. Desde ese momento, científicos heterodoxos y académicos de la agroecología, muy vinculados al trabajo de campo y a pedagogías como la de Paulo Freire o la escuela de Investigación Acción Participativa en Sociología, y el movimiento mundial de La Vía Campesina, han ido de la mano.

En tanto artista y miembro del ISEC (Instituto de Sociología y Estudios Campesinos) y de la Plataforma Rural, la cuestión fundamental a la que me enfrentaba era cómo sería una cuarta dimensión de la agroecología. Es decir, cómo generar sistemas que no sólo sean ambientalmente sostenibles, socialmente justos y económicamente viables, sino también culturalmente vivificantes ${ }^{4}$. Para ahondar en estas cuestiones era necesario abrir un debate público a escala nacional con resonancia internacional sobre el tema y sobre todo, iniciar una práctica experimental que fuera validando (o no) ciertas formas de hacer.

En 2009 se concertan los apoyos de, por un lado, el Ministerio de Medio Rural y Medio Ambiente, y del Ministerio de Cultura, por otro. Era la primera 
vez que dos altos cargos de estos ámbitos se reunían. En la misma mesa, que simbolizaba la voluntad del proyecto, también había un representante de la Plataforma Rural, otros de la academia (facultades de Bellas Artes y de Agroecología) y comisarios y directores de museo por parte del sistema del arte. Todos ellos conformaban un comité asesor, que va reuniéndose con cierta periodicidad durante la duración propuesta del proyecto, 3 años.

En 2010 se lanza públicamente con una Conferencia Internacional sobre Arte y Medio Rural en el Museo Reina Sofía; durante tres días, 200 participantes y expertos de diferentes campos y partes del mundo se daban cita para trazar una semblanza del estado de la cuestión: arte y ruralidad en la España hoy ${ }^{5}$.

En ese momento existían en Europa planteamientos teóricos por otros centros de arte (como Grizedale Arts en Inglaterra) que acogen artistas en residencia, o grupos de artistas como MyVillages (Holanda y Alemania) que trabajan sobre la cuestión. Pero no se daba esta intención de acercar poder político, institución cultural y organizaciones de base social con el objetivo de activar la reflexión y la práctica a escala nacional como trataba Campo Adentro ${ }^{6}$.

La idea de fondo era generar una sacudida y un movimiento a imagen de lo que fueron las misiones pedagógicas de la Segunda República y, antes de estas, los trenes y barcos de agitación que tras la Revolución Rusa recorren todo el país con artistas de vanguardia como el poeta Maiakosvki, los pintores El Lissitsky y Kazimir Malevich, los cineastas Dziga Vertov y Alexandre Medvedkine, combinando lenguajes creativos en un esfuerzo de comunicación y movilización sin precedentes. Ciertamente, sin esos mismos medios, ni un compromiso político cultural tan importante, Campo Adentro se embarca en 2011 y 2012 en un programa de producción artística mediante residencias en 22 pueblos por todo el país. Estos lugares, a modo de casos paradigmáticos, que van desde El Ejido a una aldea de montaña Cántabra, o a un pueblo de colonización en Badajoz, se eligen junto con los aliados de la Plataforma Rural. Se reciben más de 400 propuestas para la convocatoria de ideas, y tras un retiro a modo de cursillo acelerado sobre lo rural para los 11 artistas seleccionados y 11 invitados, se inicia el trabajo de campo. Las propuestas fueron muy diversas (desde una deriva y teoría psicogeográfica situacionista aplicada a una pueblo ya conurbación de Vigo, a un laboratorio de microorganismos y fermentos en Villarrubia -Córdoba-, Cádiz o un mapa sonoro de S. Bartomeu de Grau, en la provincia de Barcelona), al igual que los resultados ${ }^{7}$.

Algunos proyectos fueron muy exitosos, como la reconstrucción de una antiguo establo abandonado que se torna Pequeño Museo de lo Comunal en Almonaster la Real (Huelva), por parte de la artista Susana Velasco, y
5

"Vemos como en parte se percibe lo rural como una 'otredad', vista con aprensión y distancia unas veces, con idealizado bucolismo otras. En cualquier caso parece necesario examinar este reservorio de memoria, de saberes, de relaciones con la atención que merece en un momento incierto de transformación radical. El reencuentro entre campo y ciudad puede ser clave para la transición de nuestras sociedades hacia la sostenibilidad", escribe Fernando García-Dory en el programa de mano de la Conferencia Internacional Campo Adentro, MNCARS, 2010.

6

A excepción de algunos intentos de crear un Rural Cultural Forum por parte del oscuro think-tank británico llamado Littoral Arts, bajo la tutela de Ian Hunter.

7

Para verlos todos y los blogs-diarios de los artistas en sus residencias, consúltese la sección de Archivo 2010-13 en http://www.inland. org/es> [Consulta 30/09/2019]. 
Personajes de la performance El Lamento del Tritón de Fernando García-Dory. Bienal de Gwangju, Corea, 2016 | foto Campo Adentro
Véase la enjundiosa polémica en 2004 entre Claire Bishop y Nicolas Bourriaud al respecto en <https://academicworks.cuny.edu/gc pubs/96/> [Consulta: 30/09/2019].

Véase Towards a Lexicon of Usership, de Stephen Wright, con algun enfoque distinto del Arte Útil de Tania Bruguera.

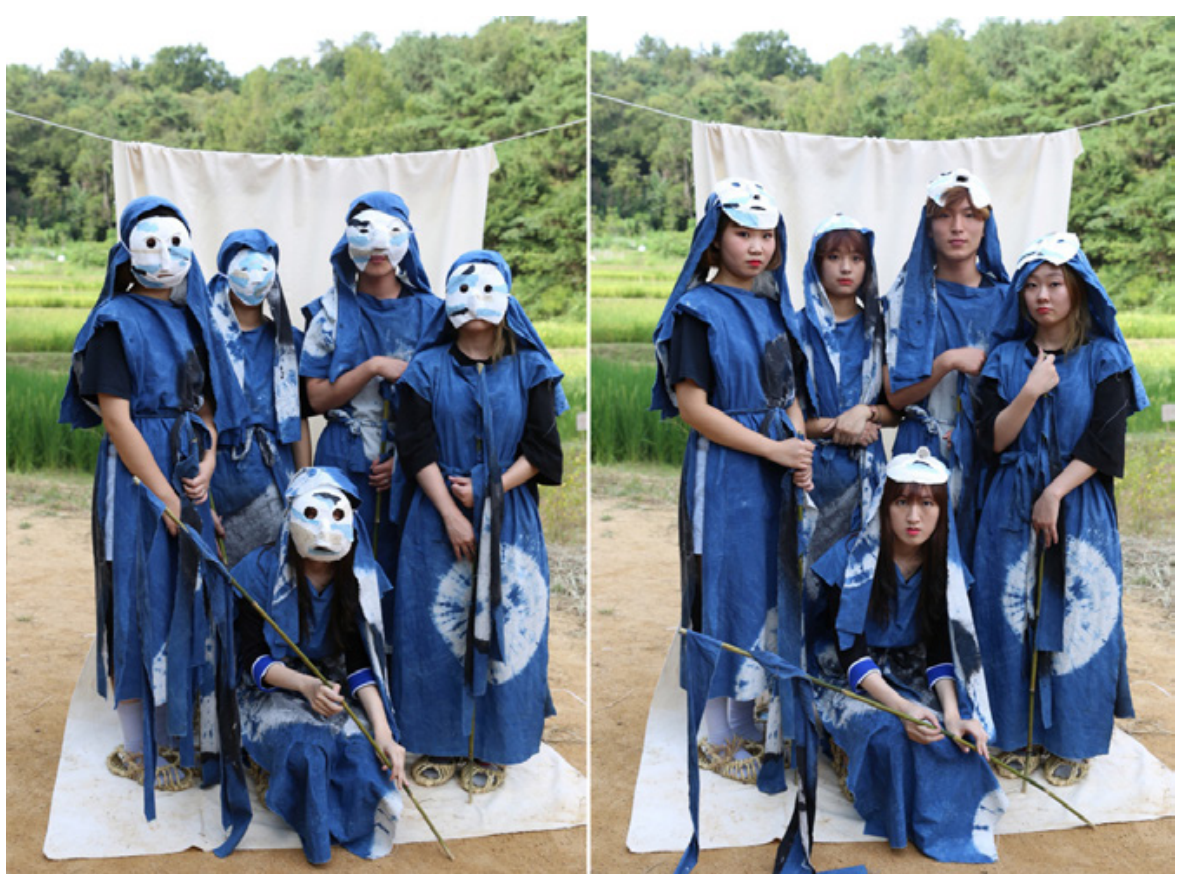

con el resto del pueblo, y que contiene obra gráfica del pastor local, Miguel "El Pajarito", o la renovación del repertorio musical local de mano de Paco Arroyo y Fonoteca 2.0; hasta la desastrosa idea de un grupo de artistas de crear una escuela "para enseñar a los locales a cuidar del medioambiente" en la comarca leonesa donde el Plan 42 de dinamización rural como medida integral para frenar los incendios había tenido lugar durante unos 10 años.

Tras cada uno de los 22 proyectos en los pueblos, se hizo una exposición local y otras dos anuales colectivas en museos en Madrid, como forma de traer el resultado del proceso a la ciudad.

Si bien cada artista tuvo total libertad creativa, tanto para la selección como durante el acompañamiento de los proyectos y la mediación local, se siguió una claro enfoque que, superando aspectos del arte público y del Land-Art, se acercaban más al arte público crítico, "Arte Relacional Antagonista"8 y del Arte Útil de Stephen Wright $^{9}$, que entroncarían con la noción de plástica social de J. Beuys, primando el proceso antes que el objeto, y la co-generación antes que la autoría individual. Se parte de la atención a un contexto territorial y social específico, y a una visión del artista como facilitador catalizador con una manifiesta intención de ofrecer una acción útil, antes que una obra de pura contemplación.

En este sentido, Alejandro Alonso Díaz, comisario participante de Campo Adentro, opina que el proyecto "toma de una genealogía del género artís- 
tico del paisaje, subvertiéndolo y deconstryéndolo al mismo tiempo, en tanto categoría estética occidental, donde el observador se sume en un medio de relaciones complejas, y esforzado por el ser-hacer, la ontología campesina-indígena"10.

Los resultados de ese primer periodo de producción mostraron los límites de algunas de las hipótesis de ese impulso inicial:

"Hemos visto que los agentes rurales todavía tienen que entender mejor los mecanismos culturales y apropiarse de ellos, y eso lleva tiempo y trabajo. La administración es incapaz de generar políticas de un mínimo compromiso más allá del cortoplacismo, y el mundo del arte está más blindado de lo que podría pensarse a estas propuestas de renovación"11.

Las dinámicas de interacción entre el arte contemporáneo y los públicos no versados son siempre complejas. Hay que encontrar lenguajes de encuentro, para esa dicotomía creada entre alta cultura/cultura popular. Hay una mutua influencia entre artista y público, que pasa de ser receptor pasivo a agente en el proceso creativo. La apertura y receptividad en los pueblos, valiéndose el artista de las herramientas adecuadas, muchas de ellas propias de la agroecología y la sociología, puede llevar casos de co-generación cultural que rompan con la especialización y diferenciación entre artista y productor cultural, a las que el sistema globalizado del arte nos tiene acostumbrados. Pero para ello, el modelo de artista en residencia, con unos dos meses escasos de estancia máxima, y una visión de "obra de autor" aún muy marcada, quedaba en evidencia como inadecuado.

En 2013 se inicia un periodo de reflexión con la creación de un Grupo de Estudios y un Servicio de Publicaciones que lanza la colección Cuadernos de Campo. Y en ese cuestionamiento, un rechazo de la idea de proyecto espectáculo, centrífugo, y la necesidad de quedar en parte fuera de foco para poder nutrir relaciones más ricas en el seno del propio grupo, que para entonces empieza a decantarse a partir de personas diversas que van participando de las diversas acciones de Campo Adentro, y con contextos de trabajo en un compromiso a medio-largo plazo. Toma así cuerpo la idea de un proyecto en constante mutación y de para-institución.

Organizada por ejes de trabajo, combina la producción agraria con la cultural lo que da base a una economía mixta (buscando una independencia de ayudas públicas y privadas y sus posibles condicionamientos), y las intervenciones en diferentes lugares en base a invitaciones de instituciones del sistema del arte ${ }^{12}$ con una labor continuada en espacios de trabajo propios. A fecha de hoy, está el edificio en Madrid Ilamado Centro de Acercamiento a lo Rural, una aldea abandonada que se está recuperando en la cornisa cantábrica, y una antigua abadía en la Sierra de la Tramuntana, Mallorca.
10

"Más allá de la decoración del 'paisaje' con parques de esculturas, apostamos por el paisanaje, y en concreto por actividades productivas como la agricultura, pesca o explotación forestal que implican manejo de los recursos naturales en base a un corpus de conocimiento concreto. De ahí que hablemos de "agriculturas" en plural, de modelos de uso de la tierra" (García Dory en una entrevista de 2011).

11

Bea Espejo entrevista a Fernando García Dory en El Cultural, 22 de marzo de 2013 <https:// elcultural.com/Fernando-Garcia-Dory> [Consulta: 29/09/2019].

\section{2}

INLAND ha participado en la Bienal de Estambul en 2015 y, ese mismo año, en Casco Art Projects Holanda, PAV Torino Italia, Maebashi Museum Japón. En 2017 se ha presentado en Contemporary Arts Glasgow, MALBA, Matadero Centro de Arte Madrid, Museo de Arte Moderno Medellin Colombia y con acciones de campo en Italia (TRANSART Festival Bolzano y Puglia) y en la Bienal de Jeju, Corea del Sur. En 2019 desarrolla un programa de estudios con Serpentine Gallery (Londres) y Matadero Madrid y exposiciones con Centro Pompidou (París) y Savvy (Berlín). 
Las acciones se multiplican, con numerosos dispositivos pedagógicos tales como la Escuela de Pastores ${ }^{13}$, el Grupo de Estudios de Ecologías, Nuevo Curriculum, por el que se trabaja con casi una docena de universidades para componer conocimientos de arte, agroecología, arquitectura o ingeniería del paisaje y formar así al artista/agente rural del futuro. Y también se acrecienta la infraestructura del proyecto, con una estación de radio, taller de autoedición, colmado-tienda, cantina, colmenar o laboratorio de lácticos.

Estamos en un momento en el que parte de los objetivos iniciales del proyecto se han cumplido: hay hoy un amplio debate social y hasta de estado sobre la cuestión rural, y en el medio artístico hay un reconocimiento y un interés en explorar este campo. Los centros de arte de mayor renombre internacional programan exposiciones y seminarios, y se multiplican espacios de arte que reivindican crear una nueva cultura rural. Podría quedar la duda del rigor y profundidad de estas manifestaciones de interés, y el riesgo que conllevan de una saturación de acepciones de nuevo urbanocéntricas del campo como lugar de escape y garante de esencias en apariencia antinómicas a la ciudad.

Por otro lado, Por otro lado, en la confusión de loas y elegías a una idea de "naturaleza/ salvaje" podemos perder de vista un acercamiento real a lo que sería el campo hoy. Investigadores especializados coinciden en que este ensamblaje de referentes, algunos de ellos materiales en tanto sustratos de producción y otros culturales, que está inserto en sistemas globales de mercado y ámbitos de decisión política supranacionales, no es en sí diferente en su constitución de lo urbano, salvando la densidad. Es por tanto sobre todo un espacio de proyección de posibilidades por grupos de interés diversos, y que objetivamente, en su progresiva despoblación, se sitúa en posición desfavorable en cuanto a servicios $u$ oportunidades.

El objetivo fundamental ahora es asentar la práctica en nuestros espacios de trabajo, desarrollar la formación y pensar y experimentar con esas formas de intervención sobre el terreno, y de generación de conocimiento y aprendizaje.

Sobre la primera cuestión, estamos ensayando dos aproximaciones. Una parte de la teoría especulativa, y de la dislocación temporal como forma de afrontar los cambios en el territorio, los retos presentes, y futuros plausibles, deseables y distópicos del lugar al que nos aproximamos. Este ejercicio de ficciones sobre paisajes lo hemos insertado como herramienta dentro de una investigación acción-participativa, en conjunto con actores locales, como forma de desatar un proceso creativo.

También entretejemos ahora dos redes. Por un lado, la que hemos llamado senda, reuniendo espacios de arte independientes latinoamericanos cam- 
po-ciudad. A modo de grupo de estudio, estamos pensando, escribiendo y reuniendo lecturas sobre posibles conjuntos como:

> Dispositivos de convivencia, estructuras de mediación, el anfitrión y el huésped.

> Lecturas, mitos y visiones, de la ciudad y el campo, del otro.

> Ecología de las prácticas.

> Frente al despojo y violencia.

$>$ Nostalgias.

$>$ Extinción.

Por otro lado, en Europa promovemos una alianza llamada Confederacy of Villages (Confederación de Pueblos) con cinco prácticas situadas en el territorio, vinculadas a reunir arte, artesanía y agricultura en maniobras cotidianas que difuminen las lineas entre utilidad y emoción.

Los retos principales que enfrentamos como proyecto vienen ahora al definir nuestro quehacer en tanto grupo de nueve personas, dispersas entre campo y ciudad, y de navegar la revueltas y oscuras aguas de una identidad en constante cambio: ¿somos el marco para la creación de otros artistas, o proveeremos el contenido a modo de tentativa de respuesta a las preguntas de partida? ¿lograremos el equilibrio de ingresos y peso entre cultura-agricultura y urbano-rural ? ¿podremos generar alianzas e incluso naturalezas híbridas entre trabajador agrario y cultural? ¿hay vida creativa más allá del arte contemporáneo? 